V. 1 - $\mathrm{N}^{\mathrm{o}} 01$ - Ano 2021

ISSN: 2763-5724 | https://www.periodicojs.com.br/index.php/hs

\title{
PERFORMANCE OF THE NURSE IN FRONT OF THE USER VICTIM OF TRAUMA CAUSED BY FIREARMS PROJECTILES: AN EXPERIENCE REPORT
}

\author{
Maria Eduarda Bezerra Lopes ${ }^{1}$ \\ Werlídya Kácia Lopes Vieira ${ }^{2}$ \\ Jacqueline Souza Nascimento da Silva ${ }^{3}$ \\ Ana Clara Souza Lima ${ }^{4}$ \\ Jéssica Barreto Pereira ${ }^{5}$
}

Abstract: Firearm trauma is considered one of the main reasons for morbidity and mortality in Brazil. In view of its destructive capacity of organs and tissues that come into contact with the fragments of the bullet. This work aims to report the experience of three students of the nursing course, facing the care of a patient with a firearm. This is a descriptive, qualitative, experience report type study. In the present study, it was possible to envision the application of the nursing process in its entirety, which allowed us to think of a plan based on the process of rehabilitation and healing of the patient. Going up a discussion about the violence in the country, since it is taking a high mortality rate between 15 to 24 years. Based on the construction of this work, it is suggested to create new research that addresses in a qualitative and quantitative way the impact of cases of violence in today's society.

Keywords: mortality; morbidity; firearm; nursing.

\section{INTRODUÇÃO}

Os casos de violência urbana sofrem ascendência com o passar dos anos e têm constituído o leque de assuntos relevantes para a saúde pública na atualidade. As tentativas de homicídio são a expressão máxima da violência interpessoal, e a prática concernente ao uso de projéteis de arma de fogo é a principal causa de morte entre jovens na faixa etária entre 15 e 24 anos no Brasil (HETTE et al, 2018).

\footnotetext{
${ }^{1}$ Enfermeira pela Uninassau- João Pessoa-PB

${ }^{2}$ Enfermeira pela Uninassau- João Pessoa-PB

${ }^{3}$ Enfermeira pela Uninassau- João Pessoa-PB

${ }^{4}$ Enfermeira. Atuante na atenção Hospitalar- João Pessoa- PB.

${ }^{5}$ Enfermeira. Mestra em Enfermagem pela Universidade Federal da Paraíba- UFPB- João Pessoa.
} 
O trauma é apontado pela Organização Mundial de Saúde (OMS) como a doença do século XXI, tendo grande impacto nas sociedades, visto que debilita pessoas em idade reprodutiva, de maneira que quando sobrevivem, têm maior tempo de hospitalização. Dessa forma, o trauma ocupa o terceiro lugar no Brasil em causas de morte: são 150 mil óbitos e 450 mil pacientes com sequelas por ano (ABREU et al, 2015).

O tratamento cirúrgico dos ferimentos que adentram a cavidade abdominal por Ferimentos por Arma de Fogo (FAF) é o tradicional padrão. Portanto, os ferimentos provocados por estes projéteis ainda são tratados com exploração cirúrgica obrigatória na maior parte dos hospitais. O motivo para essa conduta é que ainda acredita-se que exista grande incidência de lesões intraabdominais (SILVA; SORRENTINO, 2020).

A Laparatomia é definida na prática como a abertura cirúrgica da cavidade abdominal e tem como finalidade obter via de acesso a órgãos intra-abdominais em procedimentos eletivos e via de drenagem de coleções liquidas. Além disso, é um método diagnóstico (laparatomias exploratória) o qual é usado para identificar e definir a extensão de uma lesão abdominal (SILVA et al, 2020).
ISSN: 2763-5724 | https://www.periodicojs.com.br/index.php/hs

O diagnostico de enfermagem tem merecido destaque por ser fundamental para a guia de planejamento, seleção e implementação dos cuidados. Também é uma importante fonte para o conhecimento específico da profissão, favorecendo o ensino, a pesquisa e a emancipação do cliente no plano terapêutico (NOVAES; TORRES; OLIVA, 2014).

Nessa perspectiva, objetivou-se com esse estudo relatar a experiência de três alunas do curso de Enfermagem do Centro Universitário Maurício de Nassau, no cumprimento da disciplina de Estágio Supervisionado II, concluído na Clinica Médica do Hospital Estadual de Emergência e Trauma Senador Humberto Lucena (HEETSHL), no período de 09 de setembro a 5 de novembro no ano de 2020, na cidade de João Pessoa, Paraíba.

\section{METODOLOGIA}

Trata-se de um estudo descritivo, qualitativo, do tipo relato de experiência, elaborado no contexto e cumprimento da Disciplina de Estágio Supervisionado II, ministrada no décimo período do Curso de Graduação em Enfermagem do 
Centro Universitário Maurício de Nassau João Pessoa.

As atividades foram realizadas no Setor da Clínica Médica do HEETSHL durante os dias 09 de Setembro e 05 de Novembro do ano de 2020. Neste período, foi realizada a aplicabilidade do Processo de Sistematização da Assistência de Enfermagem (SAE), onde os dados foram obtidos através de observação clínica, anamnese, exames físicos regulares e consulta à Literatura para embasamento científico, objetivando evidenciar o impacto da atuação humanizada do enfermeiro frente a pacientes vítimas de trauma provocado por projéteis de arma de fogo.

Em primeiro momento, realizouse a busca por artigos que corroborassem com o tema a ser descrito neste relato, objetivando compreender as abordagens dos estudos publicados na atualidade. Para a pesquisa, utilizou-se a base de dados da Biblioteca Virtual em Saúde (BVS) e o veículo de busca Google Acadêmico, a fim de fundamentar e aproximar o estudo das contribuições científicas e das práticas de cuidado em enfermagem.

As tarefas realizadas durante $\mathrm{o}$ período de estágio foram desde atividades multidisciplinares, até $\mathrm{o}$ desenvolvimento de procedimentos privativos à Enfermagem. Dentre estas atribuições pode-se citar: Diluição e Administração de Medicamentos, a fim de contribuir com a Equipe Técnica de Enfermagem; Monitorização de sinais vitais, a fim de acompanhar a estabilidade do paciente; Realização de Hemoglicoteste (HGT), objetivando monitorar pacientes com alteração glicêmica. Ademais, foram feitas coletas para a realização de exames do tipo Hemocultura e Urocultura; Instalação e manutenção de Acessos Venosos Periféricos (AVP); Manutenção de Acesso Venoso Central (AVC); Administração de Terapias Nutricionais Enterais (TNE) e Parenterais (TNP); Curativos, em parceria à Comissão de Pele do Hospital; Cuidados Paliativos a pacientes oncológicos; Realização de Eletrocardiograma; Instalação de Sondas vesicais de alívio (SVA) e demora (SVD); Instalação de Sondas nasogástricas (SNG) e nasoenterais (SNE); Manuseio de bombas de infusão; Aspiração de vias aéreas; e aplicabilidade do Processo de Enfermagem.

RESULTADOS E DISCUSSÃO 
Durante o período referente ao cumprimento da carga horária prática da disciplina de Estágio Supervisionado II foi possível observar inúmeros casos de ferimentos decorrentes de projéteis de arma de fogo no HEETSHL, permitindo à equipe de estágio em Enfermagem vivenciar e aplicar as habilidades técnicas e científicas em indivíduos que sofreram este tipo de violência.

O presente relato discorrerá em volta do caso do paciente L. P. S, sexo masculino, 23 anos de idade, solteiro, histórico familiar de Hipertensão Arterial Sistêmica (HAS), vítima de ferimento provocado por arma de fogo, com orifício de entrada em região toracolombar esquerda e saída em hipocôndrio esquerdo. $\mathrm{O}$ paciente deu entrada no Hospital no dia 30 de julho de 2020 referindo dor abdominal intensa e foi encaminhado para o setor cirúrgico para submissão à Laparotomia exploratória para lavagem de cavidade abdominal e inserção de bolsa de Bogotá. Segundo informações colhidas no prontuário, o paciente passou a ser reabordado a partir deste episódio, em média, a cada 72 horas.

A busca dos dados para este estudo deu-se entre os dias 23 e 25 de
Setembro, no setor de clínica médica ao qual o paciente estava interno. A pesquisa foi realizada pela equipe em campo de estágio à beira-leito sob aplicabilidade do Processo de Sistematização da Assistência de Enfermagem (SAE), dando-se ênfase à primeira etapa desta sistemática. A etapa foi seguida pela realização do exame físico céfalo-podálico e avaliação de sinais vitais, respeitando-se a individualidade e limitações do paciente; ademais, realizaram-se orientações não farmacológicas para o paciente e sua acompanhante, a fim de diminuir a angústia e fortalecer o vínculo com os mesmos.

Para a construção dos diagnósticos de enfermagem utilizou-se a North American Nursing Diagnosis Association 2015-2017 (NANDA 20152017) com base nos achados clínicos do paciente. As informações coletadas foram categorizadas e organizadas para o desenvolvimento do roteiro assistencial. $\mathrm{Na}$ Tabela 1, é possível observar a aplicabilidade da SAE que norteou o plano de cuidados individual do paciente.

Tabela 1: SAE: Diagnósticos e Intervenções de Enfermagem ao paciente vítima de FAF. 


\begin{tabular}{|c|c|c|c|c|}
\hline CÓD. & $\begin{array}{l}\text { Achados } \\
\text { Clínicos }\end{array}$ & $\begin{array}{l}\text { Diagnósticos de } \\
\text { Enfermagem }\end{array}$ & $\begin{array}{l}\text { Intervenções de } \\
\text { Enfermagem }\end{array}$ & Implementação \\
\hline D1 & $\begin{array}{c}\text { Temperatura } \\
\text { corporal } \\
\text { elevada } \\
\mathrm{T}=39^{\circ}\end{array}$ & $\begin{array}{c}\text { Hipertermia } \\
\text { caracterizada por pele } \\
\text { quente ao toque e } \\
\text { fatores relacionados à } \\
\text { trauma. }\end{array}$ & $\begin{array}{c}\text { - Aplicar compressas } \\
\text { frias em têmporas e } \\
\text { regiões axilar e inguinal; } \\
\text { - Monitorizar } \\
\text { temperatura a cada } 4 \\
\text { horas; } \\
\text { - Administrar fármacos } \\
\text { antitérmicos; } \\
\text { - Avaliar resposta à } \\
\text { terapêutica } \\
\text { medicamentosa. }\end{array}$ & $\begin{array}{l}\text { Promover a } \\
\text { termorregulação. }\end{array}$ \\
\hline D2 & $\begin{array}{l}\text { Distensão e dor } \\
\text { abdominal }\end{array}$ & $\begin{array}{c}\text { Constipação } \\
\text { caracterizada por } \\
\text { abdômen distendido e } \\
\text { dor abdominal }\end{array}$ & $\begin{array}{c}\text { - Orientar ingesta } \\
\text { hídrica; } \\
\text { - Orientar posição de } \\
\text { conforto para alívio da } \\
\text { dor; } \\
\text { - Solicitar } \\
\text { acompanhamento } \\
\text { nutricional; } \\
\text { - Solicitar avaliação } \\
\text { médica. }\end{array}$ & $\begin{array}{c}\text { Promover } \\
\text { evacuação e } \\
\text { melhorar padrão de } \\
\text { eliminação. }\end{array}$ \\
\hline D3 & Sonolência & $\begin{array}{l}\text { Fadiga caracterizada } \\
\text { por sonolência e } \\
\text { fatores relacionados à } \\
\text { condição fisiológica. }\end{array}$ & $\begin{array}{l}\text { - Avaliar fatores } \\
\text { fisiológicos relacionados } \\
\text { à fadiga; } \\
\text { - Avaliar sono e repouso. }\end{array}$ & $\begin{array}{l}\text { Melhorar padrão de } \\
\text { repouso. }\end{array}$ \\
\hline D4 & Baixo peso & $\begin{array}{l}\text { Nutrição } \\
\text { desequilibrada: menor } \\
\text { que as necessidades } \\
\text { corporais com fatores } \\
\text { relacionados à } \\
\text { incapacidade de digerir } \\
\text { os alimentos. }\end{array}$ & $\begin{array}{c}\text { - Solicitar avaliação } \\
\text { nutricional. }\end{array}$ & $\begin{array}{l}\text { Melhorar padrão } \\
\text { nutricional. }\end{array}$ \\
\hline D5 & Angústia & $\begin{array}{l}\text { Ansiedade relacionada } \\
\text { à morte com fatores } \\
\text { relacionados a } \\
\text { experiência de quase- } \\
\text { morte. }\end{array}$ & $\begin{array}{c}\text { - Realizar escuta ativa; } \\
\text { - Tranquilizar e observar } \\
\text { fatores que levam à } \\
\text { ansiedade; } \\
\text { - Solicitar } \\
\text { acompanhamento } \\
\text { psicológico. }\end{array}$ & $\begin{array}{c}\text { Promover conforto } \\
\text { e esperança. }\end{array}$ \\
\hline D6 & $\begin{array}{l}\text { Incisão } \\
\text { cirúrgica }\end{array}$ & $\begin{array}{l}\text { Integridade tissular } \\
\text { prejudicada } \\
\text { caracterizada por } \\
\text { tecido lesado associado } \\
\text { à fatores mecânicos. }\end{array}$ & $\begin{array}{c}\text { - Observar presença de } \\
\text { sinais flogísticos; } \\
\text { - Avaliar lesão; } \\
\text { - Realizar curativo. }\end{array}$ & $\begin{array}{c}\text { Promover } \\
\text { integridade tissular. }\end{array}$ \\
\hline D7 & $\begin{array}{l}\text { Sinais } \\
\text { flogísticos }\end{array}$ & $\begin{array}{l}\text { Risco de infecção com } \\
\text { fatores relacionados a } \\
\text { procedimento invasivo }\end{array}$ & $\begin{array}{c}\text { - Monitorar sinais } \\
\text { flogísticos; } \\
\text { - Monitorar sinais vitais. }\end{array}$ & Prevenir infecção. \\
\hline
\end{tabular}




\section{Fonte: Própria autoria, 2020.}

Anualmente, cerca de seis milhões de pessoas de todos os grupos etários e econômicos morrem em decorrência de ferimentos não intencionais e violência. Em todo o mundo, estas são listadas como as principais causas de morte nos primeiros quarenta anos de vida e as responsáveis pela redução de anos de vida produtiva à frente das doenças cardíacas e do câncer. O manejo dos pacientes vítimas de traumas abdominais seguem protocolos de acordo com o tipo de trauma e com base nos aspectos hemodinâmicos. Grande parte dos ferimentos abdominais provocados por projéteis de arma de fogo apresentam uma taxa de lesão interna em cerca de $97 \%$ dos casos, fator que corrobora para o alto índice de laparotomias exploratórias realizadas neste tipo de paciente (PIMENTEL et al, 2019).

Hette et al (2018) em seu estudo realizado com a base de dados do Sistema de Informação de Vigilância de Violência e Acidentes da cidade de São Paulo (SIVVA), constataram que a incidência dos casos de violência se dão em suma no período noturno, em vias públicas e em cerca de $25 \%$ dos casos de vítimas de ferimentos por arma de fogo, a agressão se dá por parte de ladrões ou assaltantes. Vale salientar, que o paciente retratado no presente estudo autorrelatou que seu trauma foi proveniente de uma tentativa de assalto em seu município de residência.

Uma análise epidemiológica realizada por Silva et al (2017) atestou que cerca $95,4 \%$ dos pacientes traumatizados com lesões e perfurações por arma de fogo são do sexo masculino e apenas 4,6\% são pessoas do sexo feminino. Em relação ao grupo etário, $47,7 \%$ dos indivíduos possuem entre 20 e 29 anos.

São inúmeros os fatores que podem dificultar a assistência prestada a indivíduos com FAF. De maneira geral, a extensão e gravidade dos ferimentos e o trajeto que o projétil pode realizar no interior dos tecidos, se alojando em vasos e outras estruturas internas, são fatores que podem dificultar a decisão de conduta. O processo de Enfermagem exige do enfermeiro coordenar as ações 
da equipe, prestar cuidados de enfermagem de maior complexidade à pacientes graves e executar prescrições médicas. Ademais, deve-se avaliar a necessidade de reanimação da vítima, ofertar oxigênio suplementar se necessário e prevenir ou tratar estado de choque (ALVES et al, 2016).

A enfermagem também é responsável por registrar e documentar todos os processos e ações sistematizadas realizadas de maneira individual e coletiva. O processo de Enfermagem compreende cinco etapas sistemáticas, sendo o diagnóstico, planejamento e a avaliação da assistência, etapas privativas do enfermeiro. A aplicabilidade do processo de enfermagem possibilita a prestação de cuidados de maneira individualizada centradas nas necessidades humanas básicas, dando norte às tomadas de decisão nas mais diversas situações vivenciadas pelo gestor da equipe de enfermagem (ALMEIDA et al, 2016).

\section{CONSIDERAÇÕES FINAIS}

O presente estudo permitiu evidenciar que os casos de violência são de grande relevância para a saúde pública, visto que, é a principal causa de morte entre jovens na faixa etária entre
15 e 24 anos no Brasil, principalmente no grupo do gênero masculino. A enfermagem também é responsável por assistir pacientes vítimas de violência, de modo especial àqueles indivíduos vitimas de traumas mecânicos provocados por projéteis de arma de fogo. A aplicabilidade da SAE possibilita a prestação de cuidados de maneira individualizada centradas nas necessidades humanas básicas, dando norte à tomada de decisão nas mais diversas situações vivenciadas pelo gestor da equipe.

Nesta perspectiva, o Processo de Enfermagem deu norte à conduta da equipe de estágio frente à assistência do paciente L.P.S. vítima de trauma abdominal por FAF, dando ênfase e sempre respeitando suas limitações e suprindo as necessidades humanas básicas alteradas. Deste modo, a enfermagem torna-se imprescindível no que tange ao planejamento do cuidar holístico e humanizado dirigido aos pacientes vítimas de traumas violentos e tentativas de homicídio, visto que, estes indivíduos necessitam de uma abordagem de cuidado integral, que atendam as dimensões físicas, psicológicas e sociais.

A partir da construção deste trabalho, sugere-se a criação de novas pesquisas que abordem de maneira 
qualitativa e quantitativa o impacto dos casos de violência na sociedade atual, como também, delineie os pontos de vista dos profissionais de saúde que prestam assistência a estes casos, principalmente à equipe de enfermagem, que se posiciona de maneira integral na assistência e prestação de cuidados.

\section{REFERÊNCIAS}

ABREU, E. M. S. et al. Impacto de um protocolo de cuidados a pacientes com trauma torácico drenado. Revista do Colégio Brasileiro de Cirurgiões, v. 42, n. 4, p. 231-237, 2015.

ALMEIDA, R. A. et al. Violência e acidentes: Percepção do Enfermeiro sobre a assistência e o registro. Ciências Biológicas e de Saúde Unit, v. 3, n. 3, p. 13-26, 2016.

ALVES, J. H. S. et al. Condutas de enfermagem diante das vítimas de ferimentos por armas de fogo em serviço de atendimento móvel de urgência. Revista Brasileira de Educação e Saúde, v. 6, n. 3, p. 17-22, 2016.

Diagnóstico de enfermagem da NANDA: definições e classificação 2015-2017. Organizadoras: T. Heather
Herdman, Shigemi Kamitsuru; tradução:

Regina Machado Garcez; revisão técnica: Alba Lucia Bottura Leite de Barros, et al. Porto Alegre: Artmed, 2015.

HETTE, A. N. et al. Estudo descritivo dos casos notificados de vítimas com ferimentos por projéteis de arma de fogo ocorridos na cidade de São Paulo. Arquivos Catarinenses de Medicina, v. 47, n. 2, p. 194-203, 2018.

NOVAES, L. S.; TORRES, M. M. Diagnósticos de enfermagem em clínica cirúrgica. Acta Paulista De Enfermagem, v. 28, n. 1, p. 26-31, 2015.

PIMENTEL, S. K. et al. Tomografia no trauma abdominal grave: risco justificável. Revista do Colégio Brasileiro de Cirurgiões, v. 46, n. 1, 2018.

SILVA, F. A. et al. Tratamento fisioterapêutico no pós-operatório de laparotomia. Journal of the Health Sciences Institute, v. 28, n. 4, p. 341-44, 2010.

SILVA, F. E.; SORRENTINO, B. C. Tratamento seletivo não operatório para ferimentos penetrantes por projéteis de 
arma de fogo na parede anterior do abdômen: revisão narrativa da literatura. Journal of the Health Sciences Institute, v. 47, n. 1, 2020.

SILVA, L. A. P. et al. Análise retrospectiva da prevalência e do perfil epidemiológico dos pacientes vítimas de trauma em um hospital secundário.

Revista de Medicina, v. 96, n. 4, p. 246$254,2017$. 